Tohoku J. Exp. Med., 2004, 204, 299-308

\title{
Hypolipidemic Drugs Can Change the Composition of Rat Brain Lipids
}

\author{
Marek Vecka, Eva Tvrzická, Barbora Staňková, František Novák, ${ }^{1}$ \\ Olga NovÁKovÁ and Aleš ŽáK \\ First Faculty of Medicine, Charles University, Prague, Czech Republic, \\ ${ }^{I}$ Department of Biochemistry and ${ }^{2}$ Department of Animal Physiology, Faculty of \\ Science, Charles University, Prague, Czech Republic
}

Vecka, M., Tvrzická, E., Staňková, B., Novák, F., Nováková, O. and Žák, A. Hypolipidemic Drugs Can Change the Composition of Rat Brain Lipids. Tohoku J. Exp. Med., 2004, 204 (4), 299-308 - Hypolipidemic drugs are potent serum cholesterol lowering agents used for prevention of coronary heart disease. In addition to their cholesterol lowering effect, these drugs exhibit both pleiotropic beneficial and various neurological side effects. Therefore, we analysed effect of the hypolipidemic drugs, fenofibrate and statins, on membrane lipid composition in the rat brain tissue. Male Wistar rats were given $0.1 \mathrm{mg}$ of fenofibrate, lovastatin, pravastatin, fluvastatin or placebo (control) once daily for six weeks. In rats treated with lovastatin or pravastatin, decreased cholesterol and increased ceramide monohexoside contents in the brain tissue were observed in comparison with control. Treatment with fluvastatin or lovastatin resulted in increased sphingomyelin and decreased diphosphatidylglycerol contents. The most important changes in the fatty acid profile were observed in ceramide monohexosides; treatment with fluvastatin decreased the content of saturated and increased the content of polyunsaturated fatty acids. Fenofibrate treatment led to decreased content of saturated fatty acids in phosphatidylethanolamines. In conclusion, statin treatment resulted in the decreased content of cholesterol and diphosphatidylglycerol associated with the increased content of sphingolipids in the rat brain tissue. As cholesterol and sphingolipids are important components of brain membranes, the observed alterations in the composition brain lipids might be involved in genesis of neurological and mental symptoms following statin therapy. - statin; fibrate; brain; lipids; fatty acid

(C) 2004 Tohoku University Medical Press

Received August 11, 2004; revision accepted for publication October 20, 2004.

Address for reprints: Marek Vecka, MSc, 4th Department of Medicine, U Nemocnice 2, 12808 Praha 2,

Czech Republic.

e-mail: marvec@volny.cz 
Most of the mortality and morbidity in developed countries is caused by coronary heart disease (CHD) (Murray and Lopez 1997; Kannel 1998). The main reason of CHD is atherothrombosis. Atherosclerosis is further manifested as cerebrovascular disease (stroke), and peripheral vascular disease, respectively (Gonzalez and Kannewurf 1998).

Pharmacotherapy of above-mentioned disorders stems from well-known facts that the normolipidemic population has lower risk for development of atherosclerosis (Martin et al. 1986) and that there is positive impact of hypolipidemic treatment in primary and secondary prevention (Bucher et al. 1999). Number of papers have described the effect of hypolipidemic drugs on levels of cholesterol and triacylglycerols in serum (Illingworth and Tobert 1994) and on the liver lipid metabolism (Alegret et al. 1998), but there are only a few studies focused on other tissues e.g. skin (Wolf et al. 1999), vascular wall (Bellosta et al. 1998) and eye-lens (De Vries and Cohen 1993).

In addition to their cholesterol lowering effect, the hypolipidemic drugs exhibit both pleiotropic beneficial effects (Liao 2002), and various adverse consequences. Statins (reversible competitive HMG-CoA reductase inhibitors) can alter sleep efficiency (Vgontzas et al. 1991), cause headaches (Ditschunheit et al. 1991), myopathy (Reijneveld et al. 1996; Nakahara et al. 1998), and increase creatine kinase level (Reijneveld et al. 1996). Fibrates (endogenous PPAR $\alpha$ ligands influencing the catabolism of TAG rich particles and the expression of lipoprotein lipase, apo C-III, A-I and A-II [Schoonjans et al. 1996; Staels 2000]) can cause skin reactions (Wolf et al. 1999), renal dysfunction (Lipscombe 2001) and, in some cases, the disorders of the nervous system (Sgro and Escousse 1991). Moreover, the fibrate therapy achieved a disappointing impact on total mortality in some studies (Pedersen 1998; Bucher et al. 1999).

The reported side effects of statins and fibrates on the central nervous system deserve high interest, because these serum lipid lowering drugs can affect brain membrane lipids as well. For this reason, we decided to study the effect of three widely used statins, pravastatin (PRA), lovastatin (LOV) and fluvastatin (FLU), and fenofibrate (FEN), on the composition of the rat brain lipids.

\section{Methods}

Male Wistar rats (body weight $350 \pm 45 \mathrm{~g}$, mean \pm S.D.) were assayed for serum cholesterol and triacylglycerols. The rats were subsequently divided into 5 groups (eight animals each) with similar statistical distribution of cholesterol and triacylglycerols $(\mathrm{TAG})$ values $(1.80 \pm 0.20$ and $1.20 \pm 0.45 \mathrm{mmol} . \mathrm{l}^{-1}$, respectively). The rats were housed four per standardized cage. All procedures were performed according to the Guidelines set by Institutional Animal Use and Care Committee of Charles University.

The rats were dosed for six weeks with 0.1 mg of fenofibrate (Lipanthyl ${ }^{\mathrm{TM}} 200 \mathrm{M}$, Laboratoires Fournier, Dijon, France), fluvastatin (Lescol $^{\mathrm{TM}}$, Sandoz Pharma Ltd., Basle, Switzerland), lovastatin (Mevacor ${ }^{\mathrm{TM}}$, Merck \& Co., Inc., Whitehouse Station, NJ, USA) or pravastatin (Lipostat ${ }^{\mathrm{TM}}$, Bristol-Myers Squibb S.p.A., Anagni, Italy) in $0.5 \mathrm{ml}$ phosphate buffered Saline (PBS) $(w / v)$ with gastric tube once daily. The control group was given placebo $(0.5$ $\mathrm{ml}$ of PBS). Rats were fed ad libitum with commercial diet DOS 2BSt (Velaz, Czech Republic) and had free access to tap water and were kept under standard conditions (room temperature $22 \pm$ $1^{\circ} \mathrm{C}$, relative humidity $65 \pm 5 \%$, lighting 12 $\mathrm{h} /$ day). The last day after overnight fasting, the animals were anaesthetised with thiopental (Spofa, Czech Republic, $60 \mathrm{mg} / \mathrm{kg}$, i.p.) and sacrificed. Venous blood (containing $1 \mathrm{mg} / \mathrm{ml}$ EDTA) was collected from vena cava inferior and then centrifuged at $300 \mathrm{~g}$ for $10 \mathrm{~min}$. The brains were removed, washed in the physiological saline, lyophilised and stored at $-60^{\circ} \mathrm{C}$.

The plasma samples were analysed for glucose, total protein, urea, creatinine, fructosylamine, triacylglycerols, phospholipids, total cho- 
lesterol, HDL-cholesterol, alanine aminotransferase, aspartate aminotransferase and bilirubin with automatical analysator Technicon RA-1000 (Technicon, Robbinsville, NJ, USA) using the kits from Boehringer Mannheim GmbH Diagnostica, Germany and Lachema, Brno, Czech Republic.

Brain lipids were extracted according to the method of Folch et al. (1957). Composition of individual lipid classes was analyzed by thin-layer chromatography (TLC) with flame ionisation detection (FID) using 1-octadecanol as internal standard (Tvrzická et al. 1990). Three-step procedure with partial scan after first step was developed using mobile phases hexane/diethylether/formic acid $(45 / 15 / 0.3, \mathrm{v} / \mathrm{v} / \mathrm{v})$ for development of neutral lipids and mobile phases chloroform/methanol/ ethylacetate/water/isopropylalcohol (20/6/12/4/17, $\mathrm{v} / \mathrm{v} / \mathrm{v} / \mathrm{v} / \mathrm{v})$ and chloroform/methanol/conc. ammonia $(40 / 20 / 3, v / v / v)$ for phospholipid and ceramide monohexoside $(\mathrm{CMH})$ separation. Composition of fatty acids (FA) was determined by capillary gas chromatography with FID after previous TLC separation of the individual lipid classes (Tvrzick á et al. 2002). The mobile phase for preparative TLC was chloroform/methanol/water $(60 / 30 / 5$, $\mathrm{v} / \mathrm{v} / \mathrm{v})$. The standards of FA, phospholipids, cholesterol, and CMH were purchased from Sigma (Sigma Chemicals, St. Louis MO, USA), all the solvents used were of analytical grade.

The data were processed with one-way ANOVA statistical analysis (SigmaStat, SPSS
Science, Chicago, IL, USA) using Bonferroni post-hoc test. The accepted level of significance was 0.05 .

\section{Results}

The body weights were registered during the experiment. The final weight gain $(40 \pm 12 \%$ of initial body weight) did not differ between all groups. No changes were observed for the weight of brain, too $(0.40 \pm 0.05 \%$ of body weight $)$.

Table 1 summarizes the biochemical analysis of plasma samples. The group treated by FEN revealed increased values of plasma glucose, total protein, creatinine and fructosylamine. Plasma creatinine was also increased in all statin groups. Moreover, the group treated by FLU exhibited higher fructosylamine and total plasma protein levels. The treatment with PRA resulted in increased urea concentration. The other biochemical parameters (bilirubin, aspartate and alanine aminotransferases, triglycerides, HDL-cholesterol, total cholesterol and phospholipids) did not differ from the control groups.

The composition of brain lipids was altered by administration of hypolipidemic drugs. Cholesterol was significantly lowered in LOV $(16.8 \pm 1.4$ vs $18.6 \pm 1.3 \mathrm{mg} / \mathrm{g} \mathrm{ww}, p<0.05)$ and PRA $(16.2 \pm 1.4$ vs $18.6 \pm 1.3 \mathrm{mg} / \mathrm{g} \mathrm{ww}, p<0.05)$ groups, and diphosphatidylglycerol (DPG) was lower in LOV $(1.3 \pm 0.5$ vs $2.5 \pm 0.5 \mathrm{mg} / \mathrm{g} \mathrm{ww}, p$ $<0.01)$ and FLU $(1.8 \pm 0.4$ vs $2.5 \pm 0.5 \mathrm{mg} / \mathrm{g} \mathrm{ww}$,

TABLE 1. The effect of hypolipidemic drugs on some plasma constituents

\begin{tabular}{|c|c|c|c|c|c|}
\hline \multirow{2}{*}{$\begin{array}{c}\text { Plasma } \\
\text { parameters }\end{array}$} & \multicolumn{5}{|c|}{ Group } \\
\hline & Control & Fenofibrate & Fluvastatin & Lovastatin & Pravastatin \\
\hline glucose $\left(\mathrm{mmol.1} \mathrm{l}^{-1}\right)$ & $9.1 \pm 1.0$ & $11.8 \pm 2.2^{* *}$ & $9.2 \pm 1.1$ & $10.3 \pm 1.9$ & $8.8 \pm 1.0$ \\
\hline $\mathrm{TP}\left(\mathrm{g} .1^{-1}\right)$ & $57.2 \pm 3.0$ & $63.6 \pm 2.0^{* * * *}$ & $63.1 \pm 3.4^{* *}$ & $59.7 \pm 4.5$ & $58.9 \pm 3.6$ \\
\hline urea $\left(\mathrm{mmol} . \mathrm{l}^{-1}\right)$ & $6.4 \pm 0.3$ & $6.7 \pm 0.6$ & $6.8 \pm 0.4$ & $6.7 \pm 1.2$ & $7.5 \pm 0.7^{* *}$ \\
\hline creatinine $\left(\mu \mathrm{mol} . \mathrm{l}^{-1}\right)$ & $35.3 \pm 4.3$ & $43.1 \pm 8.7^{*}$ & $45.1 \pm 4.2^{* * *}$ & $44.9 \pm 4.6^{* * *}$ & $47.1 \pm 8.2^{* *}$ \\
\hline FRU $\left(\mu \mathrm{mol} .1^{-1}\right)$ & $129 \pm 7$ & $139 \pm 8^{*}$ & $143 \pm 13^{*}$ & $136 \pm 7$ & $134 \pm 7$ \\
\hline
\end{tabular}

In the table, the effect of hypolipidemic drugs on plasma constituents is presented. The number of observations is eight in each group. The data are in mean \pm S.D. format. The symbols for statistical significance: ${ }^{*} p<0.05,{ }^{* *} p<0.01,{ }^{* * *} p<0.001$. FRU, fructosylamine; TP, total protein. 
TABLE 2. Fatty acid content in ceramide monohexosides

\begin{tabular}{|c|c|c|c|c|c|}
\hline \multirow{2}{*}{$\begin{array}{l}\text { Fatty } \\
\text { acid }\end{array}$} & \multicolumn{5}{|c|}{ Group } \\
\hline & Control & Fenofibrate & Fluvastatin & Lovastatin & Pravastatin \\
\hline $16: 0$ & $10.18 \pm 4.69$ & $9.61 \pm 5.55$ & $7.60 \pm 1.93$ & $8.60 \pm 3.26$ & $8.76 \pm 1.86$ \\
\hline $16: 1 n-9$ & $0.42 \pm 0.28$ & $0.19 \pm 0.09^{*}$ & $0.31 \pm 0.17$ & $0.34 \pm 0.31$ & $0.41 \pm 0.28$ \\
\hline 18:0 & $18.94 \pm 2.21$ & $17.86 \pm 1.87$ & $16.16 \pm 1.73^{*}$ & $16.81 \pm 1.88$ & $17.89 \pm 2.88$ \\
\hline $18: 1 n-9$ & $22.12 \pm 4.05$ & $20.53 \pm 2.67$ & $18.81 \pm 4.48$ & $20.13 \pm 4.00$ & $21.36 \pm 2.88$ \\
\hline $18: 1 n-7$ & $4.42 \pm 0.75$ & $4.23 \pm 0.62$ & $3.96 \pm 0.76$ & $4.18 \pm 0.83$ & $4.02 \pm 0.70$ \\
\hline $18: 2 n-6$ & $1.21 \pm 0.38$ & $1.05 \pm 0.27$ & $1.13 \pm 0.42$ & $1.02 \pm 0.31$ & $1.57 \pm 0.69$ \\
\hline $20: 1 n-9$ & $3.86 \pm 1.04$ & $4.27 \pm 0.91$ & $4.06 \pm 0.51$ & $4.18 \pm 0.79$ & $4.08 \pm 0.50$ \\
\hline $20: 1 n-7$ & $1.62 \pm 0.51$ & $1.69 \pm 0.50$ & $1.54 \pm 0.40$ & $1.64 \pm 0.58$ & $2.07 \pm 1.00$ \\
\hline $20: 4 n-6$ & $10.71 \pm 2.61$ & $11.84 \pm 1.75$ & $13.89 \pm 1.72^{*}$ & $12.73 \pm 1.73$ & $12.14 \pm 1.37$ \\
\hline $20: 5 n-3$ & $0.02 \pm 0.01$ & $0.06 \pm 0.05$ & $0.06 \pm 0.03^{* *}$ & $0.04 \pm 0.02^{*}$ & $0.09 \pm 0.09$ \\
\hline $22: 0$ & $0.82 \pm 0.29$ & $0.53 \pm 0.21$ & $0.44 \pm 0.21^{*}$ & $0.57 \pm 0.24$ & $0.51 \pm 0.41$ \\
\hline $22: 1 n-9$ & $0.73 \pm 0.15$ & $0.47 \pm 0.18^{*}$ & $0.51 \pm 0.13^{*}$ & $0.59 \pm 0.18$ & $0.51 \pm 0.22$ \\
\hline $22: 4 n-6$ & $4.94 \pm 1.43$ & $5.95 \pm 1.39$ & $6.79 \pm 1.53^{*}$ & $6.13 \pm 1.22$ & $5.62 \pm 1.16$ \\
\hline $22: 5 n-3$ & $0.99 \pm 0.31$ & $1.09 \pm 0.17$ & $1.44 \pm 0.34^{*}$ & $1.41 \pm 0.31^{*}$ & $1.01 \pm 0.25$ \\
\hline $22: 6 n-3$ & $15.11 \pm 6.83$ & $17.25 \pm 3.84$ & $19.32 \pm 4.75$ & $17.80 \pm 5.26$ & $15.38 \pm 4.58$ \\
\hline$\Sigma$ sat & $31.02 \pm 5.27$ & $28.88 \pm 5.69$ & $25.17 \pm 3.32^{*}$ & $27.07 \pm 3.73$ & $28.22 \pm 3.08$ \\
\hline$\Sigma$ mono & $34.18 \pm 6.17$ & $32.12 \pm 3.19$ & $30.09 \pm 5.55$ & $31.92 \pm 5.14$ & $33.41 \pm 4.72$ \\
\hline$\Sigma \mathrm{n}-6$ & $18.58 \pm 3.25$ & $20.48 \pm 3.71$ & $23.78 \pm 3.65^{*}$ & $21.66 \pm 2.85$ & $21.79 \pm 2.65$ \\
\hline$\Sigma \mathrm{n}-3$ & $16.22 \pm 7.13$ & $18.52 \pm 4.04$ & $20.97 \pm 5.10$ & $19.35 \pm 5.53$ & $16.58 \pm 4.71$ \\
\hline
\end{tabular}

$\Sigma$, the sum; sat, saturated fatty acids; mono, monounsaturated fatty acids; n-6, n-6 fatty acids; n-3, n-3 fatty acids. The data are in molar percentage units.

The symbols for statistical significance: ${ }^{*} p<0.05,{ }^{* *} p<0.01$.

$p<0.05)$ groups. Increased values were found for $\mathrm{CMH}$ in $\mathrm{LOV}(23.2 \pm 2.4$ vs. $11.7 \pm 1.9 \mathrm{mg} / \mathrm{g}$ ww, $p<0.001)$ and PRA $(17.7 \pm 3.1$ vs. $11.7 \pm 1.9$ $\mathrm{mg} / \mathrm{g}$ ww, $p<0.01)$ groups, and for sphingomyelin $(\mathrm{SPH})$ in LOV $(4.6 \pm 0.7$ vs. $3.9 \pm 0.4 \mathrm{mg} / \mathrm{g}$ ww, $p<0.01)$ and FLU $(5.2 \pm 0.9$ vs. $3.9 \pm 0.4$ $\mathrm{mg} / \mathrm{g} \mathrm{ww}, p<0.001)$. No significant changes were observed in the FEN group.

The composition of FA in $\mathrm{CMH}$, phosphatidylethanolamine (PE), and phosphatidylcholine (PC) is shown in Tables 2-4. The most important changes were observed in CMH in the FLUtreated group. The content of saturated fatty acids (SFA), stearic (18:0) and behenic (22:0), was decreased, whereas the content of polyunsaturated fatty acids (PUFA), arachidonic acid (20:4n-6, AA), docosatetraenoic (22:4n-6), eicosapentaenoic (20:5n-3, EPA), and docosapentaenoic (22:5n-3,
DPA-3), was increased. Minor changes were observed in LOV group, increased content of EPA and DPA-3. Fenofibrate decreased two minor monoenoic acids, hexadecenoic (16:1n-9) and erucic (22:1n-9) acids. No significant changes in FA composition were observed in PRA group.

The most prominent changes of FA pattern in PE were found in FEN group. Decreased content of stearic acid contributed to the decrease of total SFA to the largest extent, compensated by increased content of docosahexaenoic acid (22:6n-3, DHA). The only significant change in FLU group was slight decrease in content of eicosatrienoic acid (20:3n-6). The other hypolipidemic drugs used (LOV and PRA) did not affect the FA profile in PE.

The hypolipidemic drugs used in our study had no effect on the FA profile in PC with the ex- 
TABLE 3. Fatty acid content in phosphatidylethanolamines

\begin{tabular}{crrrrr}
\hline \multirow{2}{*}{$\begin{array}{c}\text { Fatty } \\
\text { acid }\end{array}$} & \multicolumn{1}{c}{ Control } & Fenofibrate & Fluvastatin & Lovastatin & Pravastatin \\
\cline { 2 - 6 } $16: 0$ & $6.06 \pm 1.11$ & $5.77 \pm 0.47$ & $6.34 \pm 0.92$ & $6.68 \pm 0.96$ & $6.85 \pm 1.29$ \\
$18: 0$ & $20.04 \pm 1.63$ & $18.39 \pm 0.87^{*}$ & $20.56 \pm 3.12$ & $20.42 \pm 2.84$ & $22.26 \pm 5.41$ \\
$18: 1 \mathrm{n}-9$ & $20.00 \pm 1.40$ & $19.49 \pm 1.07$ & $20.43 \pm 2.34$ & $21.10 \pm 2.38$ & $22.10 \pm 4.13$ \\
$18: 1 \mathrm{n}-7$ & $3.70 \pm 0.31$ & $3.51 \pm 0.25$ & $3.87 \pm 0.56$ & $3.84 \pm 0.46$ & $4.15 \pm 0.91$ \\
$20: 1 \mathrm{n}-9$ & $5.09 \pm 0.56$ & $5.10 \pm 0.64$ & $5.26 \pm 0.60$ & $5.39 \pm 0.70$ & $5.64 \pm 1.21$ \\
$20: 1 \mathrm{n}-7$ & $1.34 \pm 0.16$ & $1.34 \pm 0.16$ & $1.44 \pm 0.20$ & $1.43 \pm 0.18$ & $1.48 \pm 0.33$ \\
$20: 3 \mathrm{n}-6$ & $0.61 \pm 0.05$ & $0.62 \pm 0.05$ & $0.56 \pm 0.04^{*}$ & $0.58 \pm 0.05$ & $0.56 \pm 0.08$ \\
$20: 4 \mathrm{n}-6$ & $13.58 \pm 1.21$ & $14.11 \pm 0.49$ & $13.29 \pm 1.91$ & $13.08 \pm 1.40$ & $12.11 \pm 3.65$ \\
$22: 4 \mathrm{n}-6$ & $6.86 \pm 0.51$ & $7.26 \pm 0.35$ & $6.79 \pm 0.91$ & $6.56 \pm 0.94$ & $6.07 \pm 1.72$ \\
$22: 5 \mathrm{n}-3$ & $1.29 \pm 0.28$ & $1.23 \pm 0.20$ & $1.31 \pm 0.27$ & $1.40 \pm 0.33$ & $0.99 \pm 0.41$ \\
$22: 6 \mathrm{n}-3$ & $19.04 \pm 2.40$ & $21.06 \pm 2.08^{*}$ & $17.93 \pm 4.47$ & $17.29 \pm 4.61$ & $15.45 \pm 3.70$ \\
$\Sigma$ sat & $26.75 \pm 2.00$ & $24.74 \pm 0.89^{*}$ & $27.52 \pm 3.99$ & $27.74 \pm 3.72$ & $29.74 \pm 6.84$ \\
$\Sigma$ mono & $31.04 \pm 2.40$ & $30.29 \pm 2.05$ & $31.93 \pm 3.74$ & $32.66 \pm 3.69$ & $34.31 \pm 6.58$ \\
$\Sigma \mathrm{n}-6$ & $21.78 \pm 1.56$ & $22.60 \pm 0.70$ & $21.22 \pm 2.87$ & $20.83 \pm 2.39$ & $19.41 \pm 1.81$ \\
$\Sigma \mathrm{n}-3$ & $20.43 \pm 2.52$ & $22.37 \pm 2.22$ & $19.33 \pm 4.70$ & $18.76 \pm 4.86$ & $16.54 \pm 3.82$ \\
\hline
\end{tabular}

$\Sigma$, the sum; sat, saturated fatty acids; mono, monounsaturated fatty acids; n-6, n-6 fatty acids; n-3, n-3 fatty acids. The data are in molar percentage units.

* $p<0.05$.

TABLE 4. Fatty acid content in phosphatidylcholines

\begin{tabular}{|c|c|c|c|c|c|}
\hline \multirow{2}{*}{$\begin{array}{l}\text { Fatty } \\
\text { acid }\end{array}$} & \multicolumn{5}{|c|}{ Group } \\
\hline & Control & Fenofibrate & Fluvastatin & Lovastatin & Pravastatin \\
\hline $16: 0$ & $33.72 \pm 2.97$ & $33.08 \pm 2.68$ & $34.82 \pm 2.41$ & $32.79 \pm 3.08$ & $33.92 \pm 2.18$ \\
\hline $16: 1 n-7$ & $0.47 \pm 0.07$ & $0.40 \pm 0.03$ & $0.43 \pm 0.03$ & $0.39 \pm 0.04^{*}$ & $0.43 \pm 0.03$ \\
\hline 18:0 & $17.38 \pm 1.58$ & $18.42 \pm 1.62$ & $16.71 \pm 1.40$ & $18.00 \pm 1.50$ & $16.90 \pm 1.87$ \\
\hline $18: 1 n-9$ & $22.62 \pm 1.35$ & $22.94 \pm 1.22$ & $22.92 \pm 0.64$ & $22.74 \pm 0.77$ & $22.80 \pm 0.99$ \\
\hline $18: 1 n-7$ & $6.10 \pm 0.35$ & $6.06 \pm 0.38$ & $6.33 \pm 0.15$ & $5.93 \pm 0.21$ & $5.94 \pm 0.32$ \\
\hline $20: 1 n-9$ & $1.78 \pm 0.17$ & $1.82 \pm 0.15$ & $1.89 \pm 0.38$ & $1.85 \pm 0.19$ & $1.72 \pm 0.18$ \\
\hline $20: 4 n-6$ & $6.56 \pm 1.35$ & $6.33 \pm 0.85$ & $6.17 \pm 0.78$ & $6.54 \pm 0.88$ & $6.94 \pm 0.83$ \\
\hline $22: 4 n-6$ & $1.11 \pm 0.13$ & $1.12 \pm 0.22$ & $1.11 \pm 0.11$ & $1.16 \pm 0.19$ & $1.13 \pm 0.18$ \\
\hline $22: 6 n-3$ & $6.08 \pm 0.60$ & $6.15 \pm 1.63$ & $5.81 \pm 0.83$ & $6.70 \pm 1.24$ & $6.45 \pm 1.12$ \\
\hline$\Sigma$ sat & $52.05 \pm 1.50$ & $52.46 \pm 1.25$ & $52.44 \pm 1.55$ & $51.74 \pm 1.66$ & $51.72 \pm 0.73$ \\
\hline$\Sigma$ mono & $32.40 \pm 1.68$ & $32.59 \pm 1.68$ & $33.02 \pm 1.08$ & $32.26 \pm 0.98$ & $32.27 \pm 1.24$ \\
\hline$\Sigma \mathrm{n}-6$ & $8.96 \pm 2.14$ & $8.36 \pm 0.96$ & $8.21 \pm 0.87$ & $8.60 \pm 1.03$ & $9.10 \pm 0.86$ \\
\hline$\Sigma \mathrm{n}-3$ & $6.59 \pm 0.73$ & $6.60 \pm 1.75$ & $6.33 \pm 0.86$ & $7.30 \pm 1.33$ & $6.91 \pm 1.18$ \\
\hline
\end{tabular}

$\Sigma$, the sum; sat, saturated fatty acids; mono, monounsaturated fatty acids; n-6, n-6 fatty acids; n-3, n-3 fatty acids. The data are in molar percentage units.

${ }^{*} p<0.05$. 
ception for small decrease in palmitoleic acid (16:1n-7) content in LOV group.

\section{Discussion}

The elevated glucose level in FEN group together with elevated fructosylamine level hint one of the possible effects of fibrates on carbohydrate metabolism. Fibrates enhance the expression of phosphoenolpyruvate carboxykinase that is involved in the gluconeogenesis (Schoonjans et al. 1997). The raised hexosephosphate formation in this way could consequently lead to enhanced gluconeogenesis.

The increase in plasma creatinine level, which we have observed in all hypolipidemic treated groups, might reflect the possibility of muscle tissue damage. Several cases of myopathy were reported using fibrates as well as statins (Nakahara et al. 1998), the combination of these two types of drugs being more dangerous. Moreover, fibrates are known to lower creatinine clearance (Broeders et al. 2000).

In our study, both statins and fenofibrate did not influence concentration of any plasma lipids. In the agreement with us, Fujioka et al. (1995) did not observe any effect of statins on plasma level of total cholesterol as well as LDL-cholesterol in normolipidemic rats. On the other hand, it was shown that fibrates possess hypocholesterolemic (Krause and Princen 1998) and hypotriglyceridemic (Frøyland et al. 1997) effects in rats. An explanation for this discrepancy may be a dosage of fibrates $(10-500 \mathrm{mg} / \mathrm{kg})$ usually used in other experimental studies (Fujioka et al. 1995; Alegret et al. 1998) and highly exceeding the recommended daily dosage for human which was given in our study $(0.3 \mathrm{mg} / \mathrm{kg})$.

In the FEN group, we observed hepatomegaly and tendency to gain body weight. This finding was reported as the side effect of fibrates as the $\operatorname{PPAR} \alpha$ agonists, which induce proliferation of peroxisomes leading to hepatomegaly and consequently to elevated body weight (Gaw et al. 1994).

We have demonstrated that the treatment with statins evidently influenced the composition of lipid classes in the brain tissue. Lovastatin seems to be the most potent drug decreasing cholesterol concentration, probably due to inhibition of its de novo synthesis. The fall in cholesterol was accompanied with the rise of SPH content. Both lipid classes are relevant regulators of membrane fluidity associated with optimal membrane function, which implicates hypothesis that the lower content of cholesterol may be counterbalanced with elevated SPH. Furthermore, LOV substantially increased the content of $\mathrm{CMH}$. Glycosphingolipids and their metabolic products are lipid signal molecules involved in regulation of many cellular events. Ceramides play a role as the second messengers in signal transduction (Augé et al. 1996) and their homologues are important stress signal molecules (Chatterjee 1998). It implies that the altered content of cerebrosides observed after statin treatment could cause alterations in the cell responses.

The LOV treatment brought about lowering of the DPG concentration in the brain tissue. DPG is exclusively localized within the membranes that conduct oxidative phosphorylation (e.g. inner mitochondrial membrane), where it acts as a proton-trapping molecule (Haines and Dencher 2002) and its content directly influences the activity of enzymes involved in electron transporting chain. Satoh and Ichihara (1995) described the deterioration of myocardial mitochondrial respiration during ischaemia in the rats treated with statins. Bargossi et al. (1994) observed that simvastatin decreased blood level of ubiquinone, an important component of the mitochondrial respiratory chain. DPG participates as a cofactor in translocation of cholesterol from the outer to the inner mitochondrial membrane and thus enhances the cholesterol side chain cleavage reaction (Tanaka and Strauss 1982). Low content of DPG can thus contribute to the observed cholesterol depletion.

Pravastatin and FLU are hydrophilic statins (Dujovne 1997). Their dosage did not influence the content of lipid classes to such extent as the li- 
pophilic LOV. In the PRA group, decreased cholesterol and raised $\mathrm{CMH}$ contents were observed whereas FLU dosage led to decreased DPG and increased SPH contents. Although hydrophilic statins exhibit no permeability to brain tissue (Saheki et al. 1994), the patients taking PRA have lower prevalence of Alzheimer disease (Wolozin et al. 2000). The first observation of the influence of statins on cholesterol metabolism in human brain was published two years ago, when Locatelli et al. (2002) proved simvastatin dosage to reduce the plasma levels of 24(S)-hydroxycholesterol, which is produced predominantly in the brain tissue, in patients with hypercholesterolemia. Interestingly, hydrophilic PRA was found to decrease the plasma levels of 24(S)-hydroxycholesterol in patients with Alzheimer disease, too (Vega et al. 2003). Some studies provided the evidence of lower prevalence of diagnosed Alzheimer disease and vascular dementia in hypercholesterolemic patients taking statins (Jick et al. 2000; Wolozin et al. 2000). The fact that only statins among all lipid-lowering drugs exhibit this preventive effect suggests their specific pharmacological property. The central effects of statins might be triggered at the blood brain barrier (BBB) vessel wall by the upregulation of endothelial nitric oxide (NO) production (Kirsch et al. 2003). The formation of NO is associated with apoE metabolism (Colton et al. 2002), which seems to have an important multifaceted role in CNS (Beffert et al. 1998). The effects of hydrophilic pravastatin on the brain tissue can be explained by above described mechanism starting outside BBB (Kirsch et al. 2003). In the adult rat brain, the specific activity of HMG-CoA reductase, the key enzyme involved in cholesterol biosynthesis, is regulated independently of plasma cholesterol level (Ness et al. 1979) and inside the cells, the cholesterol homeostasis is rather governed by sterol-regulatory element binding protein pathway, but the details are still lacking (Ong et al. 2000). The biosynthesis of cholesterol responds preferably to physiological requirements of the tissue, which is lower by one order of magnitude in ma- turity than after the birth (Ness et al. 1979), that is why it can be shuttled from neurons to astrocytes (Pfrieger 2002).

The FA profile was examined in main lipid classes: CMH, PE and PC. The most influenced FA profile was found in $\mathrm{CMH}$, in which the FLU treatment caused a decrease in content of 18:0, which is the main SFA, and increased content of 20:4n-6 and 22:4n-6, which are two most buoyant n-6 PUFA in CMH of rat brain. The other hypolipidemic drugs used did not substantially influence the composition of FA in CMH. The mechanisms, which were proposed to cause changes in content of lipid classes, might be further reflected in the FA profiles of these classes. In fact, $\mathrm{CMH}$ appears to be the most influenced lipid class observed if we consider the content of this lipid or its FA profile. Different effects of individual statins could be caused by variations in their chemical structure. The lipophilic statins are characterised by a $\beta$-hydroxy- $\delta$-lactone moiety, which can be converted into a water-soluble open acid form in hydrophilic statins. The other part of the molecule is based on hexahydronaphtalene skeleton for PRA and LOV, while the structure of FLU is based on indol substituted with fluorophenyl group (Endo 1992).

PE showed the most pronounced changes after FEN treatment; namely, the stearic acid content was decreased and DHA content increased. The accretion of DHA to the brain is ensured by mechanisms predominantly supplying the tissue with DHA and AA (Qi et al. 2002). This is probably associated with the importance of AA for eicosanoid formation and DHA for signal transduction (Innis 2003).

High variability of changes after statins and fenofibrate administration makes general conclusion about beneficial or detrimental character of observed lipid changes in brain very difficult within the scope of the data presented. In the case of decreased cholesterol concentration, membrane fluidity could be counterbalanced by elevated $\mathrm{SPH}$ and CMH contents. Due to the importance of cholesterol and sphingolipids in brain function, 
their alterations caused by statin treatment might be involved in the pathogenesis of neurological and mental symptoms. The effects of statins and fibrates on brain lipid metabolism should be subjects of further research.

\section{Acknowledgements}

This work was supported by grants FRVŠ 6-1479; Internal Grant Agency of Ministry of Health (grant 3596-3) and grants MSM 113100001 and MSM 113100003 from the Ministry of Education of the Czech Republic.

\section{References}

Alegret, M., Verd, J.C., Diaz, C., Hernandez, G., Adzet, T., Sanchez, R.M. \& Laguna, L.C. (1998) Effect of hypolipidemic drugs on key enzyme activities related to lipid metabolism in normolipidemic rabbits. Eur. J. Pharmacol., 347, 283-291.

Augé, N., Andrieu, N., Nčgre-Salvayre, A., Thiers, J.C., Levade, T. \& Salvayre, R. (1996) The sphingomyelin-ceramide signaling pathway is involved in oxidized low density lipoprotein-induced cell proliferation. J. Biol. Chem., 271, 1925119255.

Bargossi, A.M., Battino, M., Gaddi, A., Fiorella, P.L., Grossi, G., Barozzi, G., Di Giulio, R., Descovich, G., Sassi, S., Genova, M.L. \& Lenaz, G. (1994) Exogenous CoQ10 preserves plasma ubiquinone levels in patients treated with 3-hydroxy-3-methylglutaryl coenzyme A reductase inhibitors. Int. J. Clin. Lab. Res., 24, 171-176.

Beffert, U., Danik, M., Krzywkowski, P., Ramassamy, C., Berrada, F. \& Poirier, J. (1998) The neurobiology of apolipoproteins and their receptors in the CNS and Alzheimer's disease. Brain Res. Rev., 27, 119-142.

Bellosta, S., Bernini, F., Ferri, N., Quarato, P., Canavesi, M., Arnaboldi, L., Fumagalli, R., Paoletti, R. \& Corsini, A. (1998) Direct vascular effects of HMG-CoA reductase inhibitors. Atherosclerosis, 137, S101-S109.

Broeders, N., Knoop, C., Antoine, M., Tielemans, C. \& Abramowicz, D. (2000) Fibrate-induced increase in blood urea and creatinine: is gemfibrozil the only innocuous agent? Nephrol. Dial. Transplant., 15, 1993-1999.

Bucher, H.C., Griffith, L.E. \& Guyatt, G.H. (1999) Systematic review on the risk and benefit of different cholesterol-lowering interventions. Arte- rioscler. Thromb. Vasc. Biol., 19, 187-195.

Chatterjee, S. (1998) Sphingolipids in atherosclerosis and vascular biology. Arterioscler. Thromb. Vasc. Biol., 18, 1523-1533.

Colton, C.A., Brown, C.M., Cook, D., Needham, L.K., Xu, Q., Czapiga, M., Saunders, A.M., Schmechel, D.E., Rasheed, K. \& Vitek, M.P. (2002) APOE and the regulation of microglial nitric oxide production: a link between genetic risk and oxidative stress. Neurobiol. Aging, 23, 777-785.

De Vries, A.C. \& Cohen, L.H. (1993) Different effects of the hypolipidemic drugs pravastatin and lovastatin on the cholesterol biosynthesis of the human ocular lens in organ culture and on the cholesterol content of the rat lens in vivo. Biochim. Biophys. Acta, 1167, 63-69.

Ditschunheit, H.H., Kuhn, K. \& Ditschuneit, H. (1991) Comparison of different HMG-CoA reductase inhibitors. Eur. J. Clin. Pharmacol., 40, S27S32.

Dujovne, C.A. (1997) New lipid lowering drugs and new effects of old drugs. Curr. Opin. Lipidol., 8 , 362-368.

Endo, A. (1992) The discovery and development of HMG-CoA reductase inhibitors. J. Lipid Res., 33, 1569-1582.

Folch, J., Lees, M. \& Sloane-Stanley, G.H. (1957) A simple method for the isolation and purification of total lipids from animal tissues. J. Biol. Chem., 226, 497-509.

Frøyland, L., Madsen, L., Vaagenes, H., Totland, G.K., Auwerx, J., Kryvi, H., Staels, B. \& Berge, R.K. (1997) Mitochondrion is the principal target for nutritional and pharmacological control of triglyceride metabolism. J. Lipid Res., 38, 18511858.

Fujioka, T., Nara, F., Tsujita, Y., Fukushige, J., Fukami, M. \& Kuroda, M. (1995) The mechanism of lack of hypocholesterolemic effects of pravastatin sodium, a 3-hydroxy-3-methylglutaryl coenzyme A reductase inhibitor, in rats. Biochim. Biophys. Acta, 1254, 7-12.

Gaw, A., Packard, C.J. \& Shepherd, J. (1994) Fibrates. Handbook of Experimental Pharmacology. Hypolipidemic Agents. In: Principles and Treatment of Lipoprotein Disorders, edited by G. Schettler \& A.J.R. Habenicht, SpringerVerlag, Berlin, p. 341.

Gonzalez, E.R. \& Kannewurf, B.S. (1998) Atherosclerosis: a unifying disorder with diverse manifestations. Am. J. Health Syst. Pharm., 55, S4-S7. 
Haines, T.H. \& Dencher, N.A. (2002) Cardiolipin: a proton trap for oxidative phosphorylation. FEBS Lett., 528, 35-39.

Illingworth, D.R. \& Tobert, J.A. (1994) A review of clinical trials comparing $\mathrm{HMG}-\mathrm{CoA}$ reductase inhibitors. Clin. Ther., 16, 366-385.

Innis, S.M. (2003) Perinatal biochemistry and physiology of long-chain polyunsaturated fatty acids. J. Pediatr., 143, Suppl. 4, S1-S8.

Jick, H., Zornberg, G.L, Jick, S.S., Seshadri, S. \& Drachman, D.A. (2000) Statins and the risk of dementia. Lancet, 356, 1627-1631.

Kannel, W.B. (1998) Overview of atherosclerosis. Clin. Ther., 20, B2-B17.

Kirsch, C.H., Eckert, G.P. \& Mueller, W.E. (2003) Statin effects on cholesterol micro-domains in brain plasma membranes. Biochem. Pharmacol., 65, 843-856.

Krause, B.R. \& Princen, H.M.G. (1998) Lack of predictability of classical animal models for hypolipidemic activity: a good time for mice? Atherosclerosis, 140, 15-24.

Liao, J.K. (2002) Isoprenoids as mediators of the biological effects of statins. J. Clin. Invest., 110, 285-288.

Lipscombe, J., Lewis, G.F., Cattran, D. \& Bargman, J.M. (2001) Deterioration in renal function associated with fibrate therapy. Clin. Nephrol., 55, 39-44.

Locatelli, S., Lütjohann, D., Schmidt, H.H.-J., Otto, C., Beisiegel, U. \& von Bergmann, K. (2002) Reduction of plasma 24S-hydroxycholesterol (cerebrosterol) levels using high-dosage simvastatin in patients with hypercholesterolemia. Arch. Neurol., 59, 213-216.

Martin, M.J., Hulley, S.B., Browner, W.S., Kuller, L.H. \& Wentworth, D. (1986) Serum cholesterol, blood pressure, and mortality: implications from a cohort of 361,662 men. Lancet, 2, 933936.

Murray, C.J. \& Lopez, A.D. (1997) Mortality by cause for eight regions of the world: Global Burden of Disease Study. Lancet, 349, 1269-1276.

Nakahara, K., Kuriyama, M., Sonoda, Y., Yoshidome, H., Nakagawa, H., Fujiyama, J., Higuchi, I. \& Osame, M. (1998) Myopathy induced by HMG-CoA reductase inhibitors in rabbits: a pathological, electrophysiological, and biochemical study. Toxicol. Appl. Pharmacol., 152, 99-106.

Ness, G.C., Miller, J.P., Moffler, M.H., Woods, L.S., \& Harris, H.B. (1979) Perinatal development of 3-hydroxy-3-methylglutaryl coenzyme A reductase activity in rat lung, liver and brain. Lipids, 14, 447-450.

Ong, W.Y., Hu, C.Y., Soh, Y.P., Lim, T.M., Pentchev, P.G., \& Patel, S.C. (2002) Neuronal localization of sterol regulatory element binding protein- 1 in the rodent and primate brain: a light and electron microscopic immunocytochemical study. Neuroscience, 97, 143-153.

Pedersen, T.R. (1998) Aggressive lipid-lowering therapy: a clinical imperative. Eur. Heart J., 19, M15-M21.

Pfrieger, F.W. (2002) Outsourcing in the brain: do neurons depend on cholesterol delivery by astrocytes? BioEssays, 25, 72-78.

Qi, K., Hall, M. \& Deckelbaum, R.J. (2002) Longchain polyunsaturated fatty acid accretion in brain. Curr. Opin. Clin. Nutr. Metabol. Care, 5, 133-138.

Reijneveld, J.C., Koot, R.W., Bredman, J.J., Joles, J.A. \& Bar, P.R. (1996) Differential effects of 3-hydroxy-3-methylglutaryl-coenzyme A reductase inhibitors on the development of myopathy in young rats. Pediatr. Res., 39, 1028-1035.

Saheki, A., Terasaki, T., Tamai, I. \& Tsuji, A. (1994) In vivo and in vitro blood-brain barrier transport of 3-hydroxy-3-methylglutaryl coenzyme A (HMG-CoA) reductase inhibitors. Pharm. Res., 11, 305-311.

Satoh, K. \& Ichihara, K. (1995) Effects of 3-hydroxy3-methylglutaryl coenzyme A reductase inhibitors on mitochondrial respiration in ischemic rat hearts. Eur. J. Pharmacol., 292, 271-275.

Schoonjans, K., Staels, B. \& Auwerx, J. (1996) Role of the peroxisome proliferator-activated receptors (PPAR) in mediating the effects of fibrates and fatty acids on gene expression. J. Lipid Res., 37, 907-925.

Schoonjans, K., Martin, G., Staels, B. \& Auwerx, J. (1997) Peroxisome proliferator-activated receptors, orphans with ligands and functions. Curr. Opin. Lipidol., 8, 159-166.

Sgro, C. \& Escousse, A. (1991) Side effects of fibrates. Therapie, 46, 351-354.

Staels, B. (2000) The PPAR system and regulation of lipoprotein metabolism. In: Lipids and Vascular Disease, edited by D.J. Betteridge, Martin Dunitz Ltd., London, pp. 27-37.

Tanaka, T. \& Strauss, J.F. (1982) Stimulation of luteal mitochondrial cholesterol side-chain cleavage by cardiolipin. Endocrinology, 110, 1592-1598.

Tvrzická, E., Mareš, M., Votruba, M. \& Hrabák, P. 
(1990) Some limitations of plasma lipid analysis in clinical research by thin-layer chromatography with flame ionisation detection. J. Chromatogr. B., 530, 424-431.

Tvrzická, E., Vecka, M., Staňková, B. \& Žák, A. (2002) Analysis of fatty acids in plasma lipoproteins by gas chromatography-flame ionisation detection. Quantitative aspects. Anal. Chim. Acta, 465, 337-350.

Vega, G.L., Weiner, M.F., Lipton, A.M., von Bergmann, K., Lütjohann, D., Moore, C. \& Svetlik, D. (2003) Reduction in levels of 24S-hydroxycholesterol by statin treatment in patients with Alzheimer disease. Arch. Neurol., 60, 510-515.
Vgontzas, A.N., Kales, A., Bixler, E.O., Manfredi, R.L. \& Tyson, K.L. (1991) Effects of lovastatin and pravastatin on sleep efficiency and sleep stages. Clin. Pharmacol. Ther., 50, 730-737.

Wolf, R., Lo Schiavo, A., Russo, A., De Angelis, F. \& Ruocco, V. (1999) Effects of gemfibrozil on in vitro cultured normal human skin explants. Int. J. Dermatol., 38, 65-69.

Wolozin, B., Kellman, W., Rousseau, P., Celesia, G.G. \& Siegel, G. (2000) Decreased prevalence of Alzheimer disease associated with 3-hydroxy3-methylglutaryl coenzyme A reductase inhibitors. Arch. Neurol., 57, 1439-1443. 